\title{
Mycobacterial infection in farmed turbot Scophthalmus maximus
}

\author{
N. M. S. dos Santos ${ }^{1,2, *}$, A. do Vale ${ }^{1}$, M. J. Sousa ${ }^{3}$, M. T. Silva ${ }^{1}$ \\ ${ }^{1}$ Institute for Molecular and Cell Biology, Rua do Campo Alegre no. 823, 4150-180 Porto, Portugal \\ ${ }^{2}$ Novartis Animal Vaccines Ltd, 4 Warner Drive, Springwood Industrial Estate, Braintree, Essex CM7 2YW, United Kingdom \\ ${ }^{3}$ Instituto Nacional de Saúde Dr. Ricardo Jorge, Laboratório de Tuberculose e Micobactérias, Largo $1^{\circ}$ de Dezembro, 4000 Porto, Portugal
}

\begin{abstract}
Mycobacteriosis (piscine tuberculosis) has been reported to affect a wide range of freshwater and marine fish species; however, this is the first report describing mycobacterial infections in turbot Scophthalmus maximus. High numbers of granulomas were initially observed in the organs of moribund farmed turbot. Bacteriological analysis of organs with granulomas led to the isolation of Mycobacterium marinum. Further analysis, to determine the prevalence of the infection in the farm and to identify its source, showed the occurrence of a dual infection by $M$. marinum and $M$. chelonae. The presence of Nocardia sp. in some of the fish infected with mycobacteria was also detected. The presence of granulomas in internal organs of apparently healthy fish indicated a high prevalence of the disease, a conclusion that was supported by isolating mycobacteria from all fish with or without granulomas. The infection was probably responsible for the mortality observed (approximately $2 \% \mathrm{mo}^{-1}$ ), as most of the recently dead fish presented high numbers of granulomas and isolation of mycobacteria was possible from all of the fish. The isolation of $M$. marinum from the inlet water suggested this as the most plausible source for the infection occurring in the farm.
\end{abstract}

KEY WORDS: Turbot - Scophthalmus maximus - Mycobacteria Mycobacterium marinum - Mycobacterium chelonae Nocardia $\cdot$ Granulomas $\cdot$ Fish pathology

Resale or republication not permitted without written consent of the publisher

Mycobacteriosis has been reported to affect a wide range of freshwater and marine fish species, suggesting an ubiquitous distribution (Frerichs 1993, Belas et al. 1995). However, no information could be found on mycobacterial infections in farmed turbot Scophthalmus maximus.

In general, mycobacterioses in fish have been described as a systemic, chronic, progressive disease with granulomas scattered or grouped in virtually any parenchymatous tissue, but especially in the spleen,

*E-mail: nsantos@ibmc.up.pt kidney and liver (Frerichs 1993, Belas et al. 1995). Mycobacterium marinum, $M$. fortuitum and $M$. chelonae are the most common species found in fish (Frerichs 1993, Belas et al. 1995). Recently, 2 new mycobacterium species infecting fish have been proposed (Heckert et al. 2001, Herbst et al. 2001). In addition, $M$. marinum, $M$. fortuitum and $M$. chelonae have been reported as being capable of infecting warmblooded vertebrates, including man (Frerichs 1993).

The present work reports the occurrence of mycobacteriosis in a turbot farm in Portugal.

Materials and methods. Fish sampling and necropsy: Moribund turbot (1st sampling group) were initially collected from a turbot farm (rearing temperature of $18 \pm 1^{\circ} \mathrm{C}$ ), killed by overdose of anaesthetic (ethylene glycol monophenyl ether, Merk; $0.05 \%$ v/v) and necropsised. Head kidney, spleen and, when showing visible granulomas, other internal organs were sampled for histological, ultrastructural and bacteriological studies. For further studies concerning the prevalence of the disease in the farm, 30 recently dead (within " $1 \mathrm{~d}$; 2nd sampling group) and 19 apparently healthy (3rd sampling group) fish at harvest size (mean weight of $1213 \mathrm{~g}$ ) were collected and all the organs checked for the presence of visible granulomas. Whole head kidney and spleen from 10 recently dead (2nd sampling group) and 10 apparently healthy (3rd sampling group) fish were used for bacteriological analysis. In addition, the presence of mycobacteria was investigated in the kidney and spleen of 30 fingerlings (5 g) arriving at the farm and before transfer to the rearing tanks (4th sampling group).

Histology: Tissue samples of the organs containing granulomas from fish of the 1st sampling group were fixed in $10 \%$ buffered formalin and stained with haematoxylin-eosin (H\&E) and Ziehl-Neelsen (ZN).

Ultrastructural study: Tissue samples (1st sampling group) and isolated mycobacteria cultured in $7 \mathrm{H} 10$ 
Middlebrook broth (Difco) were fixed with $2.5 \%$ glutaraldehyde-1.0\% osmium tetroxide- $0.5 \%$ uranyl acetate (Silva et al. 1987) and embedded in Epon. Sections were contrasted with uranyl-lead (Silva et al. 1987) and viewed under a Zeiss EM 10 electron microscope.

Bacteriology: Fresh smears of isolated granulomas from the 1st sampling group were made and stained with ZN. Isolated granulomas from the 1st sampling group and whole organs from the 2nd, 3rd and 4th sampling groups, with or without granulomas, were macerated using sterile mortars and pestles and treated with the BBL Mycoprep decontamination kit according to the manufacturer's instructions (Becton Dickinson). The macerate was allowed to settle and $200 \mu \mathrm{l}$ of the supernatant were inoculated into Løwenstein-Jensen (L-J) media and incubated at $25^{\circ} \mathrm{C}$. Mycobacteria were identified by rate of growth, colonial morphology and biochemical methods including: acid-alcohol-fastness; photochromogenicity; scotochromogenicity; growth at 28,37 and $42^{\circ} \mathrm{C}_{i}$ growth on nutrient agar $\left(28^{\circ} \mathrm{C}\right)$, levulose (sole C) and mannitol (sole $\mathrm{C}$ ); growth with $5 \% \mathrm{NaCl}_{\text {; }}$ enzymatic activity (urease, $\beta$-galactosidase, nitrate reductase, arylsulfatase, catalase at $22^{\circ} \mathrm{C}$, heat-stable catalase at $68^{\circ} \mathrm{C}$, Tween 80 hydrolysis); tolerance to picric acid (0.2 mg $\mathrm{ml}^{-1}$ ); citrate and oxalate utilisation; sensitivity to thiosemicarbazone (2 and $19 \mu \mathrm{g} \mathrm{ml}^{-1}$ ), ethambutol (2 and $\left.5 \mu \mathrm{g} \mathrm{ml}^{-1}\right)$ and paraminosalicilic acid $\left(0.5 \mu \mathrm{g} \mathrm{ml}^{-1}\right)$.

Water, sediments and biofilm analysis: Five litre samples of water were collected from the inlet, rearing tank and outlet of the farm using sterile containers. Each sample was vacuum pumped through a $0.45 \mu \mathrm{m}$ pore filter, which was subsequently macerated and decontaminated as described before for the organs. Each sample was inoculated onto L-J medium (200 $\mu \mathrm{l}$; 50 L-J tubes per sample) and incubated until visible growth had occurred. In the non-contaminated samples mycobacteria were further identified using the methods mentioned above. Samples of sediments and biofilm growing on the walls of the rearing tank were also collected and decontaminated as described previously but isolation of mycobacteria was not possible because of contamination by other bacteria.

Results. Clinical signs: In general, moribund fish showed discoloration of the skin, lethargy, lack of appetite and solitary swimming. Some fish showed abdominal swelling and exophthalmia. A persistent mortality of approximately $2 \% \mathrm{mo}^{-1}$ was observed during the present study (June to October 2001), representing a 2-fold increase in the average mortality in the farm.

Post-mortem observations: Approximately $67 \%$ of the recently dead fish (2nd sampling group) showed macroscopic greyish-white granulomas scattered or grouped in various organs, especially in the kidney and spleen and less frequently in the digestive tract and liver, and $84 \%$ of apparently healthy fish with commercial size (3rd sampling group) had granulomas as described for dead fish (Table 1 and Figs. 1 \& 2). Table 1 also shows the relative amount of visible granulomas in the organs of fish from the 2nd and 3rd sampling groups. All affected fish showed enlarged spleen and kidney. None of the fingerlings showed any sign of disease and no granulomas could be observed.

Histopathology: Granulomas of varying sizes were identified in the H\&E-stained sections of organs of moribund fish from the 1st sampling group (Fig. 3). Pre-granulomatous lesions consisted of an extensive accumulation of epithelioid cells surrounded by lymphocytes. Lymphocyte infiltration was present in the entire tissue. The mature granulomas consisted of clumps of epithelioid cells surrounded by a thin fibrous capsule and often with a central area of caseous necrosis, sometimes showing a calcified centre. No Langhans giant cells were found, but atypical mononucleated giant cells were observed within the epithelioid zone of some granulomas (Fig. 4). In sections of infected organs stained with $\mathrm{ZN}$, acid-fast bacilli (frequently granular) were occasionally found (Fig. 5).

Ultrastructural characteristics: The bacteria seen in the infected organs (Fig. 6) and in the cultures (Fig. 7) showed a multi-layered cell envelope typical of mycobacteria (Silva \& Macedo 1983) with a cytoplasmic membrane and a cell wall with a peptidoglycan layer covered by an outer electron-transparent layer.

Bacteriology: Mycobacterium marinum was first isolated from granulomas from the kidney and spleen of moribund fish (1st sampling group). Mycobacteria were found in all the cultures from the recently dead (2nd sampling group) and apparently healthy (3rd sampling group) fish irrespective of the presence of granulomas. After exposure to light, 3 types of colonies could be ob-

Table 1. Scophthalmus maximus. Number of recently dead (2nd sampling group) and apparently healthy (3rd sampling group) fish with relative amount of visible granulomas in the organs. 0 , no visible granulomas; 1 , few visible granulomas; 2 , many visible granulomas

\begin{tabular}{|c|c|c|c|c|c|}
\hline & Kidney & Spleen & Digestive tract & Liver & Heart \\
\hline \multicolumn{6}{|c|}{ Recently dead fish } \\
\hline 0 & 12 & 13 & 21 & 23 & 27 \\
\hline 1 & 3 & 5 & 7 & 6 & 2 \\
\hline 2 & 15 & 12 & 2 & 1 & 1 \\
\hline $\mathrm{N}$ & & & 30 & & \\
\hline \multicolumn{6}{|c|}{ Apparently healthy fish } \\
\hline 0 & 4 & 13 & 18 & 19 & 18 \\
\hline 1 & 6 & 3 & 1 & 0 & 1 \\
\hline 2 & 9 & 3 & 0 & 0 & 0 \\
\hline $\mathrm{N}$ & & & 19 & & \\
\hline
\end{tabular}



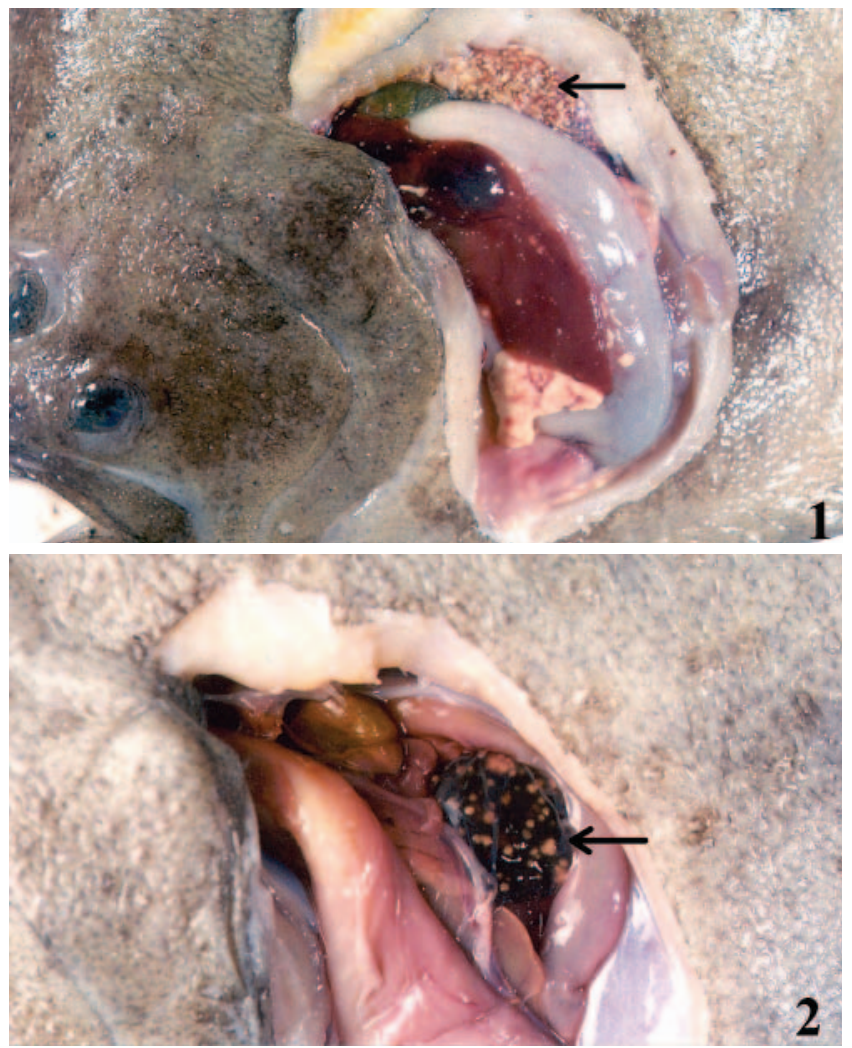

Figs. 1 \& 2. Scophthalmus maximus. Fish heavily infected by mycobacteria. Notice the granulomatous lesions in Fig. 1 kidney and Fig. 2 spleen

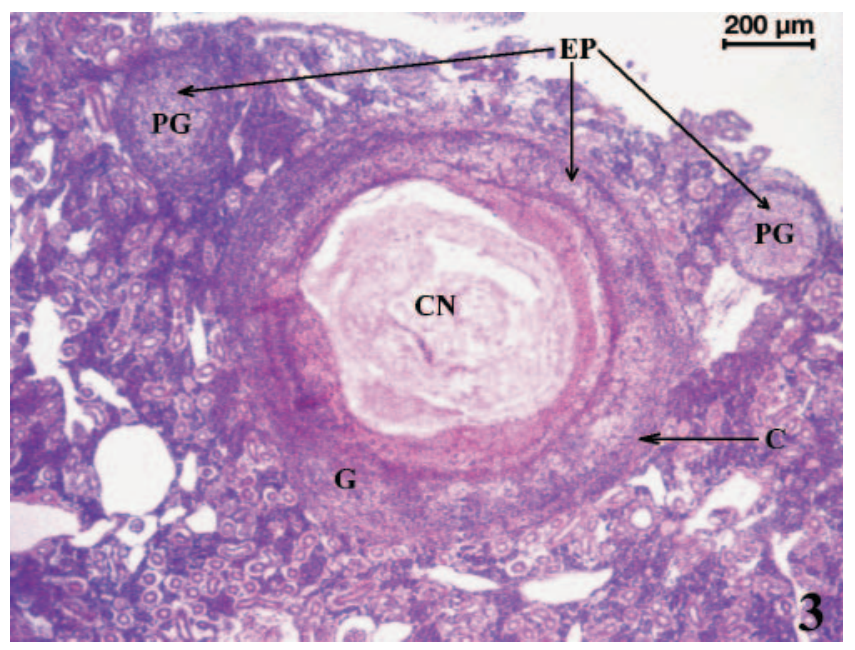

Fig. 3. Scophthalmus maximus infected by mycobacteria. Haematoxylin-eosin stained kidney granulomata at different stages of development. $\mathrm{C}$, fibrous capsule; $\mathrm{CN}$, caseative necrosis; EP, epithelioid cells; G, mature granuloma; PG, pregranulomatous lesions

served based on macroscopic observation, namely rough white-creamy colonies (biochemically identified as $M$. chelonae), rough shining orange-yellowish colonies (identified as M. marinum) and white hard-dry

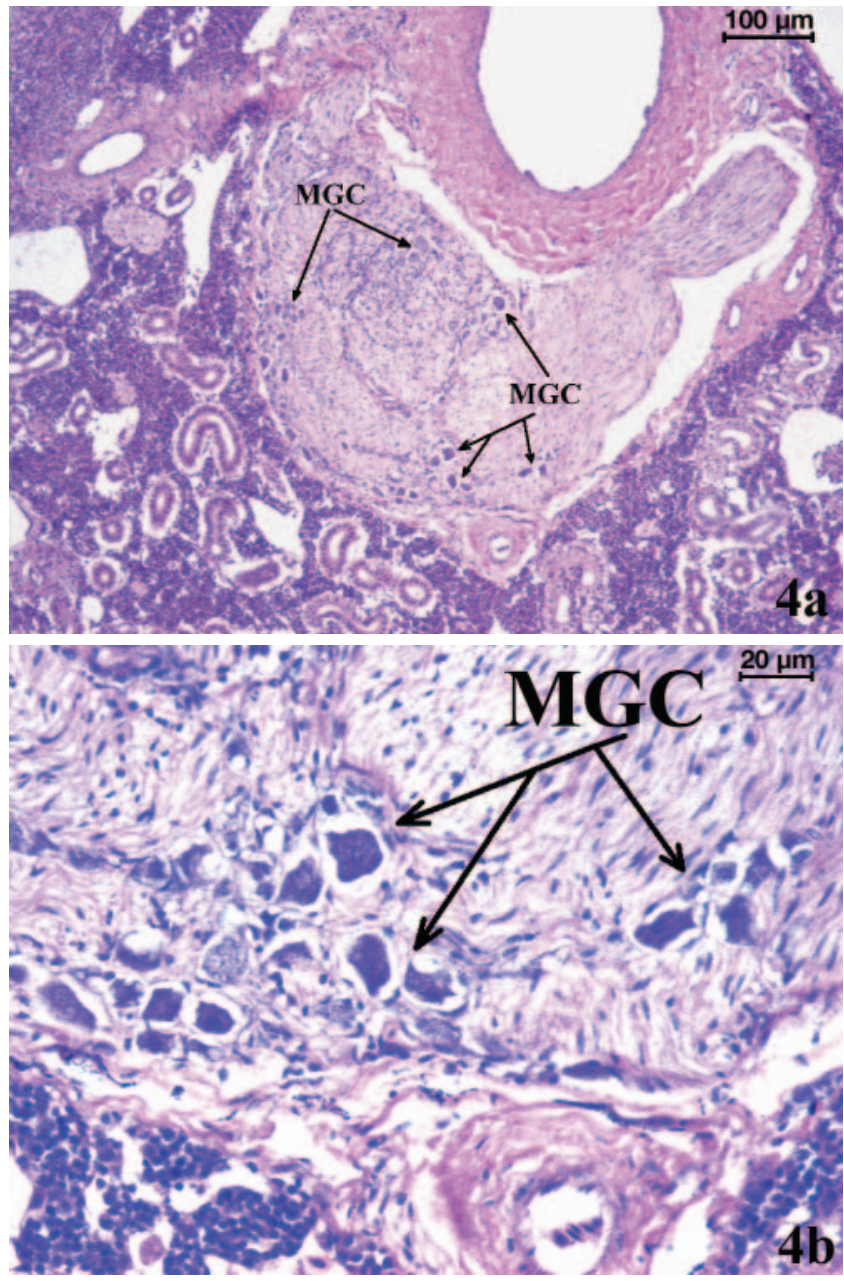

Fig. 4. Scophthalmus maximus infected by mycobacteria. (a) Atypical mononucleated giant cells (MGC) in a granulomatous lesion of kidney (haematoxylin-eosin stained). (b) Higher magnification of an area in (a)

colonies (identified as belonging to the genus Nocardia). From the 10 apparently healthy fish (3rd sampling group), M. marinum was isolated exclusively from 3 of them, $M$. chelonae exclusively from 2 of them, and both strains from the remaining 5 fish. In this group, $M$. chelonae was always found in the kidney while $M$. marinum was always in the spleen. Nocardia was isolated from the kidney of 2 fish simultaneously with $M$. chelonae. From the kidney of the 10 recently dead fish (2nd sampling group), $M$. marinum was isolated exclusively from a single fish, $M$. chelonae from 8 fish and both strains from a kidney of a single fish. Only one fish showed Nocardia, again simultaneously with $M$. chelonae. No bacteria were isolated from the kidney and spleen samples from the fingerlings. M. marinum was isolated from all the water samples, while in the outlet water $M$. fortuitum, $M$. peregrinum and $M$. aurum were also isolated. $M$. chelonae was not isolated from any of the water samples tested. 


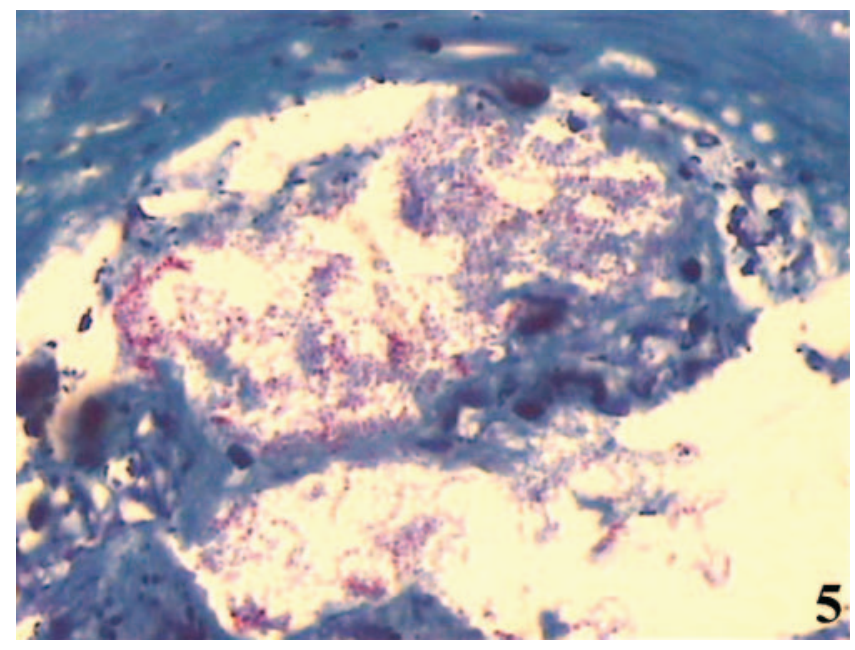

Fig. 5. Mycobacteria infecting Scophthalmus maximus. ZiehlNeelsen stain of a section from kidney of a recently dead fish. The acid-fast bacilli are extremely granular. This granularity is due to the presence of abundant lipid droplets, as shown by electron microscopy in Fig. 6. × 1000

Discussion. The present study describes a dual infection by mycobacteria in farmed turbot. Analysis of a few isolated granulomas from the kidney and spleen of moribund fish (1st sampling group) led to the identification of Mycobacterium marinum. In general, the granulomas present in the infected fish showed the same structure as those described in other fish with mycobacterial infections (Hedrick et al. 1987, Chinabut et al. 1990, Hatai \& Lawhavinit 1993, Bruno et al. 1998, Colorni et al. 1998, Diamant et al. 2000). In con-

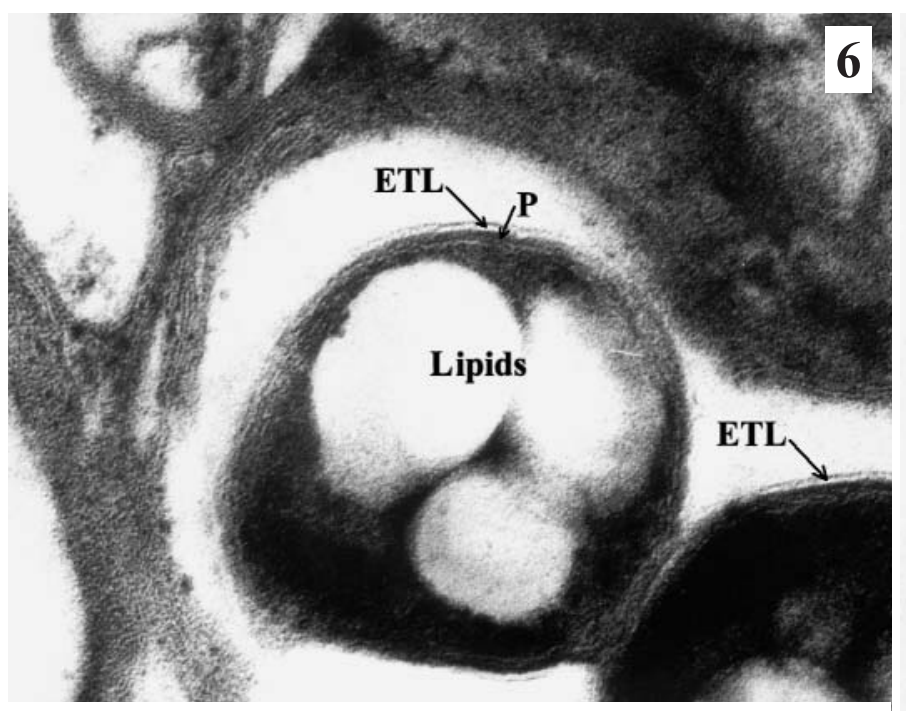

Figs. 6 \& 7. Mycobacteria infecting Scophthalmus maximus. Electron-micrograph of M. marinum in Fig. 6, the spleen and Fig. 7, the cultures, showing a multi-layered cell envelope typical of mycobacteria. CM, cytoplasmic membrane; $\mathrm{P}$, peptidoglycan layer; ETL, electron-transparent layer. Fig. 6:×75000; Fig. 7: ×67 000; Inset: ×190000 trast to previous descriptions in other fish species, a high number of mature granulomas with calcified centres and some atypical giant cells were observed in the present study. These features are described as atypical of piscine tuberculosis (Majeed et al. 1981, Chinabut et al. 1990, Hatai \& Lawhavinit 1993, Colorni et al. 1998) and closely resemble the histology of mammalian mycobacteriosis (Wolke \& Stroud 1978). In the present study few bacilli were seen in the infected tissues consistent with mammalian granulomas (Wolke \& Stroud 1978), but this varies from previous reports regarding fish mycobacteriosis (Hedrick et al. 1987, Chinabut et al. 1990, Hatai \& Lawhavinit 1993, Bruno et al. 1998, Colorni et al. 1998, Diamant et al. 2000, Heckert et al. 2001).

Since mycobacterial infections have been described in fish as causing chronic mortality with significant economic impact (Ashburner 1977, Hedrick et al. 1987, Bruno et al. 1998, Colorni et al. 1998), and have potential ability for infecting humans (Frerichs 1993, Belas et al. 1995), further analyses were carried out in order to determine the prevalence of the infection in the farm (2nd and 3rd sampling groups) and to identify its source. This led to the identification of a multiple infection by Mycobacterium marinum and $M$. chelonae as well as the presence of Nocardia sp. in some of the fish. It is difficult to draw any conclusions about the role of Nocardia in the outbreak reported here, because only a few colonies were isolated from a few fish. However, this is the first report of the isolation of Nocardia sp. from turbot, indicating that this fish species may be a potential host.

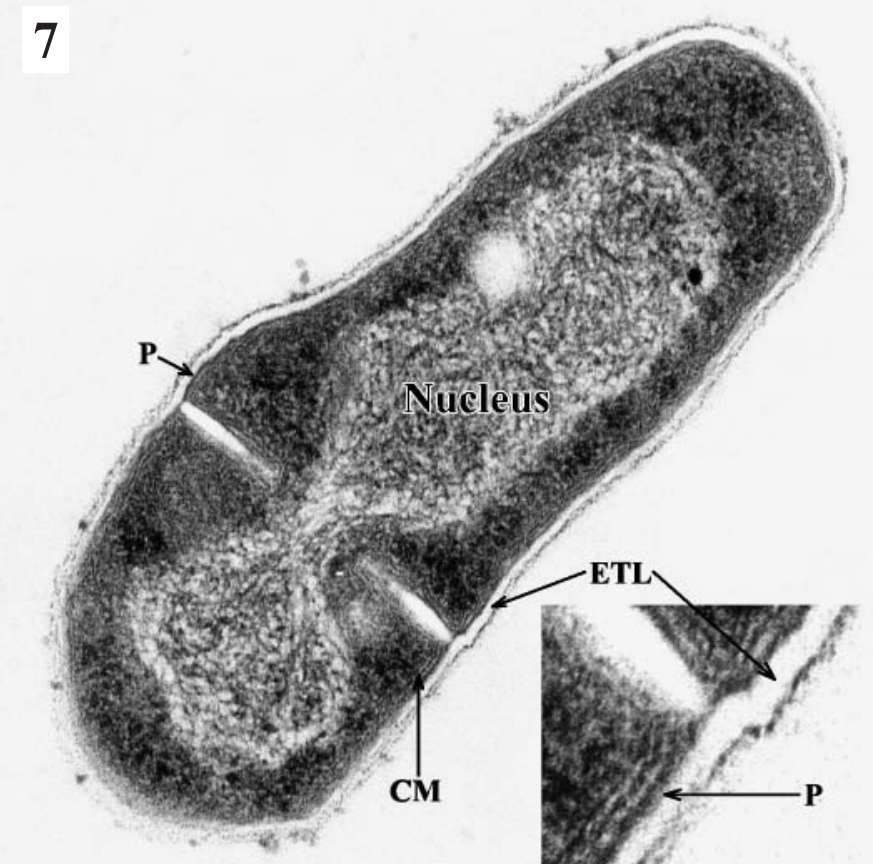


While infection by Mycobacterium marinum has been widely described in fish, infection with $M$. chelonae has so far been identified only in cold-water salmonid species, although with persistence in the salt-water phases of the life cycle of these species (Frerichs 1993, Bruno et al. 1998). Therefore, this represents the first report of the isolation of $M$. chelonae from a temperate water fish species. A curious observation was made in this study, namely, when both $M$. marinum and $M$. chelonae were present in the same fish, they were always isolated from the spleen and kidney, respectively. It is speculated that each mycobacterium may have a different port of entry or different organ specificity.

The fact that mycobacteria were isolated from all apparently healthy fish tested, even from fish without visible granulomas, indicates a high prevalence of the pathogen. Furthermore, most of the recently dead fish had high numbers of granulomas and mycobacteria were isolated from all of them, suggesting that mortalities were due to the mycobacteriosis. Under the crowded conditions prevailing in the tanks, transmission through the water, faecal products or by feeding on dead fish may have resulted in the high prevalence and subsequent mortality (Hedrick et al. 1987).

The original source of the mycobacteria found on the farm is speculative, as the long period before a clinically noticeable disease develops may mask that source. Alternatively, this may have disappeared at the time of the study. Analyses of juvenile fish just arriving at the farm from the supplier hatchery were all negative. However, the possibility of other batches brought in earlier years being responsible for the first introduction of mycobacteria into the farm cannot be excluded. Although ingestion of contaminated food is known to result in mycobaterial infection in other fish species (Chinabut et al. 1990), this source is not likely in the present situation since the farm only uses extruded food, a process that substantially reduces the prevalence of mycobacteriosis (Chinabut et al. 1990).

Mycobacterium chelonae was not isolated from any of the water samples. This could have been due to the high contamination in the samples. On the other hand, $M$. fortuitum, which has been described as infecting temperate water fish species (Frerichs 1993), while being isolated from some water samples, was not isolated from any of the fish analysed in the present study. In addition, $M$. peregrinum and $M$. aurum, which were isolated from water samples, were not found in fish.

The fact that Mycobacterium marinum was isolated from the inlet water suggests that this is the most plausible source for the infection occurring at the farm. However, the settling tanks from the waste water are located just above the inlet pumping well, and therefore it is possible that the inlet became contaminated by the effluent water.
Acknowledgements. We are grateful to Drs. Filomena Rodrigues, Fátima Gärtner, António Afonso and Anthony Ellis for helpful discussions and to Paula Macedo, Teresa Barandela and João Aveiro for their excellent technical assistance. We are also grateful to all people at the farm who assisted and contributed to the present work.

\section{LITERATURE CITED}

Ashburner LD (1977) Mycobacteriosis in hatchery-confined Chinook salmon (Oncorhynchus tshawytscna Walbaum) in Australia. J Fish Biol 10:523-528

Belas R, Faloon P, Hannaford A (1995) Potential applications of molecular biology to the study of fish mycobacteriosis. Annu Rev Fish Dis 5:133-173

Bruno DW, Griffiths J, Mitchell CG, Wood BP, Fletcher ZJ, Drobniewski FA, Hastings TS (1998) Pathology attributed to Mycobacterium chelonae infection among farmed and laboratory-infected Atlantic salmon Salmo salar. Dis Aquat Org 33:101-109

Chinabut S, Limsuwan C, Chanratchakool P (1990) Mycobacteriosis in the snakehead, Channa striatus (Fowler). J Fish Dis 13:531-535

Colorni A, Avtalion R, Knibb W, Berger B, Colorni B, Timan B (1998) Histopathology of sea bass (Dicentrarchus labrax) experimentally infected with Mycobacterium marinum and treated with streptomycin and garlic (Allium sativum) extract. Aquaculture 160:1-17

Diamant A, Banet A, Ucko M, Colorni A, Knibb W, Kvitt H (2000) Mycobacteriosis in wild rabbitfish Siganus rivulatus associated with cage farming in the Gulf of Eilat, Red Sea. Dis Aquat Org 39:211-219

Frerichs (1993) Mycobacteriosis: nocardiosis. In: Inglis V, Roberts RJ, Bromage NR (eds) Bacterial diseases of fish. Blackwell, Oxford, p 219-233

Hatai K, Lawhavinit O (1993) Mycobacterium infection in pejerrey, Odonthestes bonariensis Cuvier \& Valenciennes. J Fish Dis 16:397-402

Heckert RA, Elankumaran S, Milani A, Baya A (2001) Detection of a new Mycobacterium species in wild striped bass in the Chesapeake Bay. J Clin Microbio 39: $710-715$

Hedrick RP, McDowell T, Groff J (1987) Mycobacteriosis in cultured striped bass from California. J Wildl Dis 23: 391-395

Herbst LH, Costa SF, Weiss LM, Johnson LK, Bartell J, Davis R, Walsh M, Levi M (2001) Granulomatous skin lesions in moray eels caused by a novel Mycobacterium species related with Mycobacterium triplex. Infect Immun 69: 4639-4646

Majeed SK, Gopinath C, Jolly DW (1981) Pathology of spontaneous tuberculosis and pseudotuberculosis in fish. J Fish Dis 4:507-512

Silva MT, Macedo PM (1983) The interpretation of the ultrastructure of Mycobacterium cells in transmission electron microscopy of ultrathin sections. Int J Leprosy 51:225-234

Silva MT, Appelberg R, Silva MNT, Macedo PM (1987) In vivo killing and degradation of Mycobacterium aurum by mouse peritoneal macrophages. Infect Immun 55: 2006-2016

Wolke RE, Stroud RK (1978) Piscine mycotuberculosis. In: Montali RJ (ed) Mycobacterial infections of zoo animals. Smithsonian Institute Press, Washington, DC, p 269-275

Submitted: March 21, 2002; Accepted: July 22, 2002

Proofs received from author(s): September 9, 2002 